\title{
The Ease of Sunflower Seeds
}

\section{Nasim Habibzadeh*}

In Sport Science, School of Health and Social Care, Teesside University, United Kingdom

*Corresponding Author: Nasim Habibzadeh, In Sport Science, School of Health and Social Care, Teesside University, United Kingdom.

Received: September 03, 2019; Published: September 20, 2019

\section{Abstract}

Sunflower seeds are the fruit of the sunflower that are grown worldwide. Sunflower seeds contains amazing nutritional values. Various Sunflower seeds ease the sense of pleasures since it boost the nervous system function. Sunflower seeds are healthy snake when one's has the sense of hunger. Accordingly, sunflower seeds are potent to benefit overall health and contentment if they could place in diet every occasion.

Keywords: Sunflower Seeds; Health Outcomes; Pleasures

\section{Introduction}

Sunflower seeds are the fruit of the sunflower which are grown worldwide and contains amazing health benefits owing to include valuable nutritional components (Figure 1) [1]. Sunflower seeds are healthy snake when hunger. Any type of sunflower seed is great source of vitamin $\mathrm{E}$ which is the base of primary fat - soluble antioxidant in body that act as inflammatory in nature. Sunflower seeds are enriched in protein, unsaturated fats, fiber, selenium, copper, zinc, folate, iron also [2]. Due to this, sunflower seeds ease symptoms of premenstrual syndrome (PMS) which may delay osteoporosis in elder women [3].

Moreover, sunflower seeds are kind of means to boost emotional sense and goodness when some pleasures are demanded since they account for solo snack with delicious ingredients. Sunflower seeds are rich in the B complex vitamins, which are good - ease for a healthy nervous system [4].

Sunflower seeds are very healthy nutrients for weight loss programs as well [5]. Sunflower seeds can be added as crunch to salads since they can provide useful sense of fullness through compensating the required calories in a diet to maintain a healthy metabolism when one's has the sense of hunger. Sunflower seeds as include healthy fatty acids, can build blocks for cell membranes, at which balance hormones throughout the body systems [6]. Even though, utilizing the sunflower seeds should be in controlled manner as extra consumption of salted sunflower seeds is not appropriate in part for individual with high blood pressure.

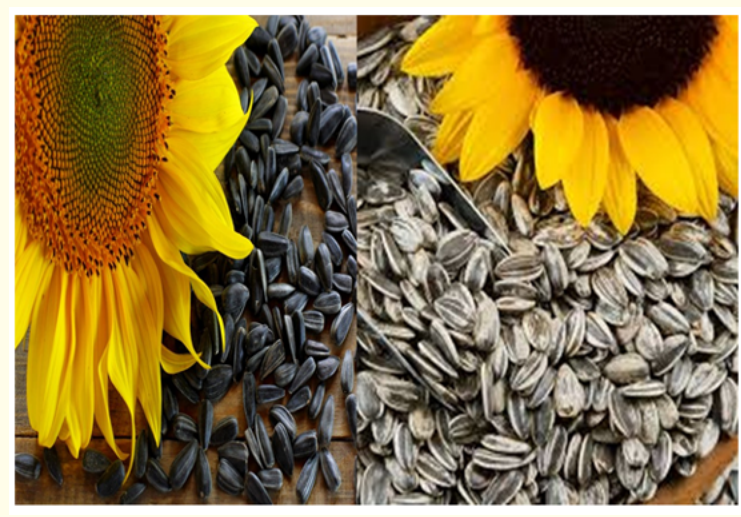

Figure 1: The sunflower seeds. 


\section{Conclusion}

Sunflower seeds hold excellent nutritional values. Sunflower seeds contain variety of vitamins and minerals. Sunflower seeds are delicious and healthy snack with valuable ingredients. Sunflower seeds naturally include healthy fat, cholesterol and protein that can be used for a healthy diet or lose weight programs. Sunflower seeds can boost the sense of goodness and pleasures in time as they reinforce the nervous system function. Therefore, the nutritional quality of sunflower seeds can serve to ease overall health and happiness.

\section{Bibliography}

1. Shuangshuang Guo., et al. "A review of phytochemistry, metabolite changes, and medicinal uses of the common sunflower seed and sprouts (Helianthus annuus L.)". Chemistry Central Journal 11.1 (2017): 95.

2. Alagawany M., et al. "The practical application of sunflower meal in poultry nutrition". Advances in Animal and Veterinary Sciences 3.12 (2015): 634-648.

3. Habibzadeh N. "Prevalence of Osteopenia among sedentary young women". East African Journal Public Health 8.1 (2011): 67-68.

4. Habibzadeh N. "Nuts, Optimum Substitutes for any Meal". Acta Scientific Nutritional Health 3.9 (2019): 96-97.

5. Habibzadeh N. "Conventional habitual nutritional changes can lead to the several health". Journal of Nutritional Biochemistry 2.1 (2018): 147-150.

6. Ivanova P., et al. "Amino acid composition and solubility of proteins isolated from sunflower meal produced in Bulgaria". International Food Research Journal 20.6 (2013):2995-3000.

\section{Volume 3 Issue 10 October 2019}

(C) All rights are reserved by Nasim Habibzadeh. 